\title{
KALVAKKANEVAN VILJELYSARVOSTA
}

\author{
LAURi Saloheimo \\ Suoviljelysyhdistyksen Karjalan koeasema, Tohmajärvi
}

Saapunut 8. 10. 1955 .

Nevat jakaantuvat useihin alaryhmiin pintakasvillisuutensa perusteella. KIVISEN mukaan (2) muodostavat $\mathrm{k}$ a l v a k k a n e vat yhden tällaisen alaryhmän. Kalvakkanevojen ravinnepitoisuus vaihtelee suuresti, parhailla niistä kasvaa jossain määrin vaateliaitakin kasveja kuten siniheinää (Molinia), järvikortetta ja saralajeja. Viljelysarvoltaan heikoimpia ovat Kivisen mukaan (2) rahkaiset kalvakkanevat sekä tupasvilla- ja luikkakalvakkanevat.

HUIKARI (1) on julkaissut Lukkalan, Kotilaisen ja Kivisen käsityksiin perustuvan taulukon erilaisten puuttomien soiden viljelys- ja metsäojituskelpoisuudesta. Alla on ote taulukon kalvakkanevoja koskevasta osasta.

\begin{tabular}{|c|c|c|c|}
\hline \multicolumn{2}{|c|}{ Suotyyppi } & Viljelysboniteetti & Metsäojitusboniteetti \\
\hline Ruohoinen & akkaneva & $6-7$ & $5-6$ \\
\hline Siniheinä- & $"$ & $5-6$ & $3-4$ \\
\hline Sara- & " & 4 & $1-2$ \\
\hline Tupasvilla- & $"$ & 2 & 1 \\
\hline Luikka- & $"$ & 2 & - \\
\hline
\end{tabular}

HUIKARI ei mainitse lainkaan rahkaista kalvakkanevaa, jolle Kivinen on antanut boniteettiluvuksi 2. Tällaisten soiden viljely edellyttää niiden käsittelyä rahkasoina eikä niitä nykyään suositella viljeltäväksi, jos parempia soita on saatavissa.

Seuraavassa esitetään Suoviljelysyhdistyksen Karjalan koeasemalla suoritetun kalvakkanevan uudisraivaus- ja viljelyskokeen tuloksia. Suon luontainen kasvillisuus oli v. 1922 Mauno J. Kotilaisen tutkimuksen mukaan: Sphagnum papillosum 5, Sph.tenellum 1, Sph.balticum 2, Mylia anomala 1. Eriophorum vaginatum 2, Scirpus caespitosus 3, Carex pauciflora 1, Andromeda polifolia 1, Vaccinium oxycoccus 1, V. uliginosum, Empetrum nigrum 1 ja Rubus chamaemorus 1. Vaikka kasvillisuusluettelon mukaan luikka on yleisempi alueella kuin tupasvilla, on näitä molempia kasveja pidettävä yhtä tärkeinä allaolevan turpeen osina. Turpeen happamuus oli 
luonnontilassa $\mathrm{pH}$ 3.4, viljelystoimenpiteillä se kohosi 5.7:ään. Rahkaturvekerroksen syvyys kuvattavan kokeen kohdalla on 1 metrin vaiheilla koko turvekerroksen ollessa 5-6 m paksu. Syvemmällä suossa vaihtelevat metsä- ja saraturpeet.

Selostettavan kokeen tuloksia vuosilta 1928 - 29 on kirjoittaja (3) selostanut jo aikaisemmin. V. 1924 varustettiin tuleva koeala ympärysojalla ja v. 1926 kaivettiin sarkaojat $20 \mathrm{~m}$ etäisyydelle toisistaan. V. 1929 syvennettiin ojat salaojitusta varten. Viljelykselle otettaessa v. 1928 ei suon pintaa aurattu eikä kuokittu, vain siellä täällä esiintyvät fuscum-mättäät poistettiin kuokalla. Kevättalvella samana vuonna ajettiin suon pinnalle hyvälaatuista hietaa $500 \mathrm{~m}^{3}$ ha:lle. Lumien lähdettyä v. 1928 levitettiin koealueelle 2 to kalkkikivijauhoa ha:lle. Peruslannoituksena sai

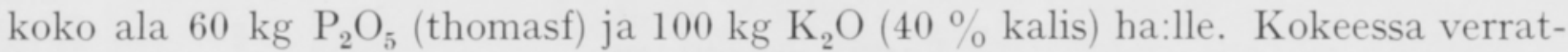
tiin toisiinsa eri typpilannoitteita käyttämällä niitä 15 ja $30 \mathrm{~kg} \mathrm{~N} / \mathrm{ha}$. Toukok. 5 pnä 1928 kylvettiin alueelle kaura ja vähän myöhemmin heinänsiementä. Vuosina 1929 - 32 kasvoi koealalla heinä ja v. 1933 jälleen kaura.

Taulukko 1 osoittaa, että kalvakkaneva-uudisviljelyksen sato on ollut vähäinen karjanlantaa vaille jätetyllä alalla, kun kohtalaisena satona pidetään 2000 ry/ha. Karjanlantaa saaneella alalla on päästy lähelle tätä tavoitetta jo uudisviljelyskaudeksi katsottavana 6 vuoden jaksona. Typpilannoitteet ovat lisänneet satoa 19-70\%:lla karjanlantaa saaneella alalla vastaavien \%-lukujen ollessa 4-148 sitä vailla olevalla saralla.

V. 1934 annettiin koko koealueelle 80 to tunkiolantaa (1/3 karjanlantaa $+2 / 3$ mutasuoturvetta) ha:lle. Samana vuonna kylvettiin kokeelle ohra sekä juhannusruis ja v. 1935 heinänsiemen. Vuosina 1936-39 kasvoi kokeessa timotei-apilanurmi.

Taulukosta 2 nähdään, että päämäärä sadon suhteen, 2000 ry/ha vuodessa, on tällä kalvakkanevalla saavutettu jo välittömästi 6 vuoden uudisviljelyskauden jälkeen. Mikäli nurmi olisi käännetty ja toinen karjanlanta-annos levitetty aikaisemmin, olisi tähän tulokseen päästy vieläkin nopeammin, olihan karjanlantaa saaneen saran keskisato jo toisena viljelysvuonna (1929) keskimäärin 2234 ry eli $5580 \mathrm{~kg} /$ ha timotei-apilaheiniä.

Kun käymme tutkimaan typen mahdollista mobilisoitumista kokeen kasvualustana olevassa papillosum-turpeessa uudisviljelyskautena 1928 - 33 ja tavallisena viljelyskautena 1934 - 39, on aluksi karjanlantaa vailla kasvanut kokeen osa jätettävä tarkastelun ulkopuolelle, koska sillä ei ole vertailukohdetta jälkimmäisen jakson aikana. Edelleen on huomioitava apilan ja toisten hernekukkaisten kasvien osuus nurmissa, koska ne ottavat typpensä suoraan ilmasta. Tämän vuoksi on nurmien sato käsiteltävä erikseen.

Kokeessa kasvaneen nurmen kasvilajit määrättiin vuosina 1930, 1932 ja 1937 toisen, neljännen ja toisen vuoden nurmista. - Taulukko 3 osoittaa, että jälkimmäinen, v. 1935 perustettu nurmi on ollut ensimmäistä monin verroin apilarikkaampi. Tämä johtuu siitä, että papillosum-turve on kyntöjen ym. muokkaustoimenpiteiden sekä uusittujen lannoitusten ansiosta käynyt myös vaateliaan apilan kasvatukselle soveliaaksi. Kokeen nurmikasvullisuuden perusteella ei tosin voida päätellä alustaturpeen typen mahdollista hyväksikäyttöä, koska apila on jälkim- 
Taulukko 1. Typpiväkilantain vertailu kalvakkanevaviljelyksellä. Sadot vuosina 1928 -33 vuotta ja ha kohti.

\begin{tabular}{|c|c|c|c|c|c|c|c|c|}
\hline \multicolumn{5}{|c|}{ Väkilannoissa annettu $\mathrm{kg} / \mathrm{ha}$} & \multicolumn{4}{|c|}{ S a t o rehuyksikköinä } \\
\hline \multirow{2}{*}{$\begin{array}{l}\mathrm{P}_{2} \mathrm{O}_{5} \\
\text { (Thf) }\end{array}$} & \multirow{2}{*}{$\begin{array}{c}\mathrm{K} 2 \mathrm{O} \\
(40 \% \mathrm{k})\end{array}$} & \multicolumn{3}{|c|}{ T y p p e ä } & \multicolumn{2}{|c|}{ Ilman karj.lant. } & \multicolumn{2}{|c|}{40 to karjanl. ha } \\
\hline & & (ks) & $(\mathrm{kt})$ & (leunas) & $\mathrm{ry} / \mathrm{ha}$ & suhdel. & ry/ha & suhdel. \\
\hline 60 & 100 & - & - & - & 360 & 100 & 1093 & 100 \\
\hline 60 & 100 & 15 & - & - & 567 & 153 & 1301 & 119 \\
\hline 60 & 100 & 一 & 15 & - & 373 & 104 & 1306 & 119 \\
\hline 60 & 100 & - & - & 15 & 642 & 179 & 1437 & 131 \\
\hline 60 & 100 & 30 & - & - & 893 & 248 & 1478 & 135 \\
\hline 60 & 100 & - & 30 & - & 599 & 166 & 1537 & 141 \\
\hline 60 & 100 & - & - & 30 & 749 & 208 & 1866 & 170 \\
\hline
\end{tabular}

Taulukko 2. Typpiväkilantain vertailu kalvakkanevaviljelyksellä. Sadot vuosina $1934-39$ vuotta ja ha kohti.

\begin{tabular}{|c|c|c|c|c|c|c|}
\hline \multicolumn{5}{|c|}{ Väkilannoissa annettu $\mathrm{kg} / \mathrm{ha}$} & \multicolumn{2}{|c|}{ S a to } \\
\hline \multirow{2}{*}{$\begin{array}{l}\mathrm{P}_{2} \mathrm{O}_{5} \\
\text { (thf) }\end{array}$} & \multirow{2}{*}{$\begin{array}{c}\mathrm{K}_{2} \mathrm{O} \\
(40 \% \mathrm{k})\end{array}$} & \multicolumn{3}{|c|}{ T y p p e ä } & \multirow{2}{*}{ ry/ha } & \multirow{2}{*}{ suhdel. } \\
\hline & & $(\mathrm{ks})$ & (kt) & (leunas) & & \\
\hline 60 & 100 & - & - & - & 2041 & 100 \\
\hline 60 & 100 & - & - & - & 2198 & 107 \\
\hline 60 & 100 & - & 15 & - & 2129 & 104 \\
\hline 60 & 100 & - & - & 15 & 2069 & 101 \\
\hline 60 & 100 & 30 & - & - & 2254 & 110 \\
\hline 60 & 100 & - & 30 & - & 2193 & 107 \\
\hline 60 & 100 & - & - & 30 & 2309 & 111 \\
\hline
\end{tabular}

Taulukko 3. Typpiväkilantain vertailu kalvakkanevaviljelyksellä. Apilan ja toisten hernekukkaisten kasvien määrä \%:eissa nurmen kasvustosta.

\begin{tabular}{|c|c|c|c|c|c|c|}
\hline \multirow{3}{*}{\multicolumn{2}{|c|}{ Väkilanta-annos kg/ha }} & \multicolumn{4}{|c|}{ Hernekukkaisia paino-\% } & \multirow{3}{*}{$\begin{array}{c}\text { v } 1937 \\
\text { k.l }\end{array}$} \\
\hline & & \multicolumn{2}{|c|}{ v. 1930} & \multicolumn{2}{|c|}{ v. 1932} & \\
\hline & & ilman k.l. & k.1. & ilman k.l. & $\mathrm{k} .1$. & \\
\hline Peruslannoitus & & 30,1 & 40,4 & 0,4 & 30,5 & 66,0 \\
\hline " $\quad+$ & $+15 \mathrm{~N} \mathrm{ks}$ & 2,7 & 6,1 & 0,8 & 13,1 & 63,2 \\
\hline " & $+15 \mathrm{~N} \mathrm{kt}$ & 0,4 & 3,1 & 0,6 & 9,8 & 65,5 \\
\hline " & $+15 \mathrm{~N}$ leunas & 3,3 & 1,6 & 0,1 & 6,9 & 56,1 \\
\hline " & $+30 \mathrm{~N} \mathrm{ks}$ & 1,7 & 18,5 & 0,9 & 18,4 & 58,6 \\
\hline$"$ & $+30 \mathrm{~N} \mathrm{kt}$ & 3,1 & 27,9 & 0,6 & 7,9 & 74,5 \\
\hline " & $+30 \mathrm{~N}$ leunas & 20,4 & 16,9 & 4,5 & 19,5 & 64,5 \\
\hline
\end{tabular}


Taulukko 4. Typpiväkilantain vertailu kalvakkanevaviljelyksellä. Nurmien keskisatomäärät vuosina $1929-32$ ja $1936-39$

\begin{tabular}{|c|c|c|c|c|c|}
\hline \multicolumn{6}{|c|}{ He in äsa to } \\
\hline \multirow{2}{*}{\multicolumn{2}{|c|}{ Väkilanta-annos $\mathrm{kg} / \mathrm{ha}$}} & \multicolumn{2}{|c|}{ vv. $1929-32$} & \multicolumn{2}{|c|}{ vv. $1936-39$} \\
\hline & & ry/ha & suhdel. & ry/ha & suhdel. \\
\hline \multicolumn{2}{|c|}{ Peruslannoitus } & 1130 & 100 & 2002 & 100 \\
\hline " & $+15 \mathrm{~N} \mathrm{ks}$ & 1287 & 114 & 2067 & 103 \\
\hline ") & $+15 \mathrm{~N} \mathrm{kt}$ & 1355 & 120 & 2049 & 102 \\
\hline " & $+15 \mathrm{~N}$ leunas & 1425 & 126 & 1947 & 97 \\
\hline ") & $+30 \mathrm{~N} \mathrm{ks}$ & 1434 & 127 & 2157 & 107 \\
\hline " & $+30 \mathrm{~N} \mathrm{kt}$ & 1560 & 138 & 2102 & 105 \\
\hline औ & $+30 \mathrm{~N}$ leunas & 1832 & 162 & 2095 & 104 \\
\hline
\end{tabular}

Taulukko 5. Typpiväkilantain vertailu kalvakkanevaviljelyksellä. Viljakasvien keskisatomäärät vuosina $1928,1933,1934$ ja 1935.

\begin{tabular}{|c|c|c|c|c|c|}
\hline \multirow{3}{*}{\multicolumn{2}{|c|}{ Väkilanta-annos kg/ha }} & \multicolumn{3}{|c|}{$\mathrm{Vilj}$ as a to } & \\
\hline & & \multicolumn{2}{|c|}{ vv. 1928 ja 1933} & \multicolumn{2}{|c|}{ vv. 1934 ja 1935} \\
\hline & & ry/ha & suhdel. & ry/ha & suhdel. \\
\hline \multicolumn{2}{|c|}{ Peruslannoitus } & 1020 & 100 & 2120 & 100 \\
\hline 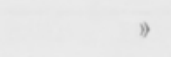 & $+15 \mathrm{~N} \mathrm{ks}$ & 1330 & 132 & 2464 & 116 \\
\hline$\Rightarrow$ & $+15 \mathrm{~N} \mathrm{kt}$ & 1207 & 119 & 2288 & 108 \\
\hline$\Rightarrow$ & $+15 \mathrm{~N}$ leunas & 1467 & 145 & 2312 & 109 \\
\hline 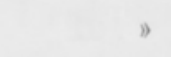 & $+30 \mathrm{~N} \mathrm{ks}$ & 1567 & 155 & 2448 & 115 \\
\hline " & $+30 \mathrm{~N} \mathrm{kt}$ & 1492 & 148 & 2372 & 112 \\
\hline 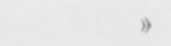 & $+30 \mathrm{~N}$ leunas & 1935 & 191 & 2736 & 129 \\
\hline
\end{tabular}

mäisessä nurmessa ollut valtakasvina. Tämä on otettava huomioon, kun tarkastetaan taulukossa 4 esitettyjä tietoja näiden molempien nurmien keskisadoista karjanlantaa saaneilla aloilla. Taulukosta havaitaan, että typpiväkilantojen satoalisäävä vaikutus on jäänyt verraten vähäiseksi joka jäsenellä jälkimmäisessä vuosien 1936 -39 nurmessa, missä se on ollut keskimäärin $3 \%$ pelkän PK-lannoituksen antamista sadoista. Vastaava keskimääräinen \%-luku on uudisviljelyskauden nurmessa vuosina 1929-1932 ollut $31 \%$. Satomäärä on myöhemmän jakson nurmessa ollut pienin koejäsenellä, jonka apila-\% taulukon 3 mukaan oli heikoin.

Lopuksi tarkastamme viljankasvatusvuosien satomääriä kokeen karjanlantaa saaneilla aloilla (taulukko 5). Vuosina 1928 ja 1933 kasvoi sillä kaura, v. 1934 ohra ja v. 1935 juhannusruis, joista mikään ei voi käyttää hyväkseen ilmakehän vapaata typpeä.

Viljasadoissa on varsinaisena viljelyskautena vv. 1934-35 ollut uudisviljelyskauteen verrattuna vastaava lisäys kuin heinällä, ja on tämä johtunut alustaturpeen viljelyskasveille edullisista muutoksista. Viljalla on typpiväkilantain vaikutus 
ollut tuntuvampi kuin heinällä. Uudisviljelyskautena on näiden aiheuttama sadonlisäys ollut keskimäärin $53 \%$ peruslannoitusruutujen sadosta. Varsinaisena viljelyskautena on tämä sadonlisäys- $\%$ alentunut $15: \mathrm{ksi}$ viljallakin. On todennäköistä, että ainakin jälkimmäisessä tapauksessa viljakasvit ovat saaneet osan käyttämästään typestä suoraan kasvualustana olevasta papillosum-turpeesta.

\section{$P \ddot{a} \ddot{t}$ elm $\ddot{a} t$}

Rahkainen kalvakkaneva on hietaa, kalkkia, karjanlantaa sekä väkilantoja saatuaan jo toisena viljelysvuonna uudisraivauksen jälkeen antanut kohtalaisen sadon, keskimäärin $5580 \mathrm{~kg}$ timotei-apilaheinää ha:lta. Myöhäisemmässä viljelyksessä on tällainen sadon määrä asettunut pysyväksi.

Typpiväkilantain satoalisäävä vaikutus on heinänkasvussa olevalla kalvakkanevaviljelyksellä uudisviljelyskautena ollut $31 \%$ peruslannoitusalan satomäärästä. Myöhemmässä viljelyksessä on tämä alentunut $3 \%$ :iin. Viljalla ovat vastaavat arvot olleet 53 ja $15 \%$.

Huomattava osuus näihin muutoksiin lienee papillosum-rahkaturpeen typellä, jonka mobilisaatiota viljelystoimenpiteet ovat edistäneet.

\section{KIRJALLISUUTTA}

(1) Huikari, Olavi, 1952. Suotyypin määritys maa- ja metsätaloudellista käyttöarvoa silmällä pitäen. Silva Fennica 75.

(2) Kivinen, Erkki, 1947. Suotiede. Helsinki.

(3) Saloheimo, Lauri, 1930. Rahkasuoviljelyksen typpilannoituksesta. Suoviljelysyhd. vuosik. 1929, p. $142-149$.

R E F E R A T :

ÜBER DEN ANBAUWERT VON SPHAGNUM FUSCÜM-MOOR

$$
\text { LAURi SALOHEIMo }
$$

Moorkulturverein, Versuchsstation in Karelien, Tohmajärvi

In dem Aufsatz wird über Urbarmachung und Anbau eines in Nordkarelien gelegenen PapillosumSphagnum fuscum-Moores berichtet. Dieses Moor hat nach Zufuhr von Feinsand, Kalk, Stallmist und Kunstdüngern schon im zweiten Anbaujahr nach der Urbarmachung einen mässigen Ertrag geliefert. Die ertragsteigernde Wirkung der Stickstoff-Kunstdünger hat bei der in Graswuchs stehenden Sphagnum fuscum-Kultur während der Neubruchzeit $31 \%$ von der Ertragmenge der Grunddüngungsfläche ausgemacht. Bei späterem Anbau ist sie auf $3 \%$ gesunken. Bei Getreide haben sich diese Zahlen auf 53 und $15 \%$ belaufen. Ein bedeutender Anteil an diesen Veränderungen dürfte dem im PapillosumSphagnum fuscum-Torf enthaltenen Stickstoff zugekommen sein, dessen Mobilisation durch die Anbaumassnahmen gefördert worden ist. 